\title{
Theorizing about faith and faithfulness with Jonathan Kvanvig
}

\author{
Daniel J. McKaughan ${ }^{1}$ (D) and Daniel Howard-Snyder ${ }^{2}$ \\ ${ }^{1}$ Department of Philosophy, Boston College, 351N Stokes Hall, Chestnut Hill, MA 02467-3806, USA \\ ${ }^{2}$ Department of Philosophy, Western Washington University, Bellingham, WA, 98229, USA \\ e-mail: daniel.mckaughan@bc.edu
}

(Received 24 January 2021; revised 11 May 2021; accepted 13 May 2021)

\begin{abstract}
What are faith and faithfulness, and how are they related? We consider two views that express very different answers to these questions. On our view, faith and faithfulness are distinct and yet complement each other. Faith is resilient reliance and faithfulness is resilient reliability, both of which involve conative and/or affective elements. In contrast, while Jonathan Kvanvig also holds that faith involves conative and/or affective elements, he identifies faith with a disposition to act in service of an ideal in the face of difficulty. However, this view of faith leads to some puzzling claims about how faith relates to faithfulness. We evaluate several claims suggested by what Kvanvig says, arguing both that his view loses sight of the distinctness of faith and faithfulness and that the inferences he wants to draw from faithfulness or faithful behaviour to faith are unjustified. Instead, we aim to show how the insights he calls to our attention can be better accommodated and explained by a more comprehensive, unified theory of faith and faithfulness and their relations.
\end{abstract}

Keywords: Faith; faithfulness; resilience; reliability; reliance; Jonathan Kvanvig

At the heart of the Abrahamic tradition stands the practice of covenant. Relationships of mutual faith and faithfulness are central to that practice. Ideally, a relationship of mutual faith and faithfulness involves both parties putting and maintaining faith in the other and both parties being faithful to the other, in accordance with the terms of the covenant. An understanding of the heart of the Abrahamic tradition, therefore, requires an understanding of faith, faithfulness, and their relationship. The same goes for secular covenants, such as marriage, and relationships of mutual faith and faithfulness experienced throughout human life, as the ancient Greeks and Romans well understood. ${ }^{1}$

Also central to the Abrahamic tradition are a variety of ideals. Further, the tradition commends to its adherents that they, individually and collectively, put and maintain their faith in those ideals and that they remain faithful to them. Naturally, the religions represented by this tradition express those ideals differently. For example, Jews are called to maintain faith in and to be faithful to the ideals expressed by living in a community dedicated to obeying the law revealed to Israel by the LORD, so as to be a light to the nations. Christians are called to maintain faith in and to be faithful to the ideals expressed in following Jesus, so as to participate in the kingdom of God on earth with all people 
willing to do the same. Muslims are called to maintain faith in and to be faithful to the ideals expressed in living in submission to Allah, as revealed by Allah's prophet, Mohammed, in the practice of the five pillars, among other things.

All this suggests that a philosophy of faith, faithfulness, and their relationship to each other is in order. So: what are faith and faithfulness, and how are they related? We find it helpful to approach these questions through reflection on Jonathan Kvanvig's writings on the topic. In what follows, we will compare and contrast what he says with an alternative theory, giving reasons to prefer the alternative, as both pertain to the relationship between faith and faithfulness and to the data to which Kvanvig appeals to support his theory. ${ }^{2}$

\section{The Identity Thesis and the Entailment Thesis}

We begin with a passage in which Kvanvig identifies 'the kind of faith' that he speaks of with faithfulness, claiming that this identity has an explanatory advantage. The kind of faith in question is 'affective faith', he says, that is, faith involving 'conative and affective elements' and 'faith worth having': 'Such an identification of affective faith with faithfulness is also well suited to explaining important and central examples of religious faith, such as the faith displayed by Abraham in leaving Mesopotamia for Canaan. ${ }^{3}$ We assess the alleged explanatory advantage later. For now, note that Kvanvig explicitly identifies affective faith with faithfulness. That 'identification' helps us interpret one of Kvanvig's chief illustrations of how faith relates to faithfulness, which immediately precedes it. After giving up a game-winning home run, a despondent Little League pitcher resolves to become better so as never to feel that way again.

Our youngster makes a commitment to a certain kind of future. It might be an intense commitment or more casual in its firmness, but when he carries through on this commitment, he will be properly characterized as being faithful to it, or pursuing his goal faithfully. In a short motto, we grasp the noun form of what (this kind of) faith is from the adjectival and adverbial form involving being full of faith: faith is what faithful people have and faith is whatever it is that underlies and explains patterns of behavior and activity that are engaged in faithfully. ${ }^{4}$

Notice two things in this passage. First, Kvanvig specifically identifies the Little League pitcher's commitment to a certain goal as faith; and when the youngster follows through on it, he is 'being faithful to it', 'pursuing his goal faithfully'. In that case, one might infer, faithfulness motivates his following through and pursuit. But the youngster's commitment just is his faithfulness, Kvanvig appears to assume - unless the boy's following through and pursuit are overdetermined by distinct mental states, his commitment, on the one hand, and his faithfulness, on the other hand, a possibility we can set aside since Kvanvig would have mentioned it if that is what he had in mind. That is: the youngster's commitment is faith, and his commitment is faithfulness; so, faith is faithfulness.

Second, Kvanvig generally identifies faith with 'what faithful people have' and 'whatever underlies and explains patterns of behavior and activity that are engaged in faithfully'. Faithfulness is what faithful people have and faithfulness is what underlies and explains patterns of behavior and activity that are engaged in faithfully - what else could it be? It follows that faith is faithfulness. That is: faith is what faithful people have and what explains faithful behavior; and, what faithful people have and what explains faithful behavior is faithfulness; so, faith is faithfulness.

We have, then, an answer to our question of how faith relates to faithfulness, accompanied by two implicit arguments for it: 
The Identity Thesis. Faith is faithfulness. ${ }^{5}$

When Frances Howard-Snyder commented on Kvanvig's presentation at Purdue University's Faith and Reason: Themes from Swinburne conference, which included the two passages we have quoted, she said this:

Imagine a couple, Adam and Eve. Adam is an adulterer. Eve is not. Imagine a conversation between Adam and his friend. The friend says, 'You've been bad, Adam. How would you like it if she did the same to you? How would you like it if she slept with someone else?' Adam replies: 'She'd never do that. I have faith in her - complete faith'. If one identifies faith with faithfulness, it follows that Adam is a faithful husband. But he is not. Eve, meanwhile is faithful to Adam. Her friend asks whether Eve has gotten back at Adam by sleeping with Jack. Eve says, 'no, currently I'm faithful to him'. Friend: 'Why not? He's unfaithful to you'. Eve: 'I know but I made a covenant that is unconditional. And I'm not going to sleep with Jack no matter what Adam does'. If one identifies faith with faithfulness, it follows that Eve has faith in Adam. But clearly she doesn't. She is faithful, but she doesn't have faith; whereas Adam has faith but he is not faithful. Moreover, this isn't an outlier case. As an example of secular faith or lack of such faith, a couple's sexual relationships seem to be more paradigmatic than a child's relation to his pitching career. ${ }^{6}$

The argument is clear: Adam retains his faith in Eve as a spouse despite being unfaithful to her in that capacity, and Eve retains her faithfulness to Adam as a spouse despite lacking faith in him in that capacity; so, faith is not identical with faithfulness. Howard-Snyder is exactly right, in our opinion.

In addition, two more reasons justify rejection of the Identity Thesis.

The claim that faith is faithfulness is no more plausible than the claim that trust is trustworthiness or reliance is reliability - which is to say that it is not plausible at all. When you attribute trust or reliance to someone, or when you ask someone to put their trust in you or to rely on you, you do not attribute trustworthiness or reliability to them or ask them to be trustworthy or reliable. The same goes for faith and faithfulness.

Further, if we identify faith with faithfulness, we'll make hash of an important feature of relationships of mutual faith and faithfulness. As indicated earlier, a relationship of mutual faith and faithfulness is a relationship in which each person puts their faith in and is faithful to the other. As such, faith and faithfulness complement each other, answer to each other, so to speak - at least when all goes well. That's because, when all goes well, if you put your faith in someone, they will respond with faithfulness, and if you are faithful to someone, they will put their faith in you. This reciprocity is absent if faith is faithfulness. So, faith is not faithfulness.

We might search for a weaker claim, for example:

The Entailment Thesis: Faithfulness entails faith.

In Kvanvig's reply to Howard-Snyder, in the Q\&A at the Purdue Swinburne conference, he backed off the 'identification' of faith and faithfulness to the Entailment Thesis:

I didn't identify faith and faithfulness. I agree with Frances that that would be a serious mistake. What I did was endorse a kind of inference from faithfulness to faith. And I didn't say whether it is monotonic or nonmonotonic. But I think it sounded like I was saying its nonmonotonic. And I think I was assuming that. I don't know what happens 
if it becomes ... Sorry ... I think I was assuming it was monotonic. I don't know what happens if it becomes nonmonotonic. But I don't think any of her examples cast doubt on the inference from faithfulness to faith. ${ }^{7}$

This won't do. To say that faith is not identical with faithfulness but that faithfulness entails faith - that's the 'monotonic inference' - is to imply that, since Eve is faithful to Adam, she has faith in him. But that's false. Moreover, mutatis mutandis, our other two reasons against the Identity Thesis apply with equal force to the Entailment Thesis.

We might search for a yet weaker claim in the neighbourhood. Notice that the Entailment Thesis speaks of faith, not affective faith, which is Kvanvig's subject matter. Perhaps 'affective' makes all the difference. That is, even though faith is not faithfulness, and even though faithfulness does not entail faith, faithfulness entails affective faith, that is, faith involving 'affective and conative elements' and 'faith worth having'. We have then the

Restricted Entailment Thesis. Faithfulness entails affective faith.

We will approach this thesis by offering a theory of affective faith and faithfulness. Then, in light of it, we will assess the thesis. (From here on, 'faith' refers only to affective faith.)

\section{A theory of faith and faithfulness}

Sometimes we put our faith in other people. Call this relational faith. Stated abstractly, our theory of relational faith is this:

Resilient Reliance. For you to have faith in someone for something is for (i) you to be disposed to rely on them to come through with respect to it, with resilience in the face of challenges to doing so, because of (ii) your positive conative and cognitive states towards their coming through.

So for you to put your faith in a surgeon to safely perform an appendectomy on your child is for you to be disposed to rely on them to do so and to be resilient in the face of challenges to relying on them, because of your positive conative and cognitive states towards their performing it safely.

Some clarification is in order. For you to be in a positive cognitive state towards someone coming through is for you to be in some state or other that represents them as coming through, has a mind-to-world direction of fit, responds to your grounds for their coming through, and disposes you to take a stand on behalf of them coming through. Propositional belief that they will come through counts as a positive cognitive state but - crucially - there are other candidates. Depending on the details, they include acceptance, credence, trust, hope, imaginative assent, and beliefless assuming. ${ }^{8}$ For you to be in a positive conative state towards them coming through is for you to be in some state or other that represents them coming through, has a world-to-mind direction of fit, and in virtue of which it matters to you (with positive valence) whether they come through. Wanting them to come through counts but - crucially - there may be other candidates, such as being for them coming through, being in favour of it, being attracted to it, being emotionally invested in it, or even wanting to want them to come through - anything in virtue of which their coming through matters to you. ${ }^{9}$ We collect both positive states under the label positive stance. For you to be resilient in the face of challenges to relying on someone to come through with respect to something is for you to be at least somewhat disposed to (try to) overcome challenges to relying on them for it, whether those challenges are evidential, emotional, or something else besides. 
On our theory, faith is a role-functional psychological state. ${ }^{10}$ Faith takes as input any of a wide variety of combinations of positive stances towards someone coming through and gives as output a disposition to rely on them to come through, with resilience in the face of challenges. Our theory's bumper-sticker reads: faith is resilient reliance.

As for relational faithfulness, to be a faithful person is not to be full of faith or especially 'faithish'. Rather, as William Alston puts it, '[a] faithful person is one who is worthy of faith being reposed in [them], trustworthy, reliable, loyal, steadfast, constant, and so on'.11 Notice that, if faith involves a disposition to rely on someone for something, a person is worthy of faith being reposed in them for it only if they are disposed to come through reliably with respect to it. Further, if faith involves resilience in the face of challenges to relying on someone for something, a person is worthy of faith being reposed in them only if they are likewise disposed to come through reliably even in the face of challenges to doing so. Putting these two points together, our theory of relational faithfulness is this:

Resilient Reliability. For you to be faithful to someone for something is for (i) you to be disposed to come through reliably with respect to it, with resilience in the face of challenges to doing so, because of (ii) your positive stance towards your coming through.

Thus, for you to be faithful to an editor, to meet the deadline, is for you to be disposed to come through reliably in meeting it and to be resilient in the face of challenges to doing so, because of your positive stance towards coming through.

As with faith, faithfulness is a functional psychological state. Faithfulness takes as input any of a wide variety of combinations of positive stances towards coming through for someone and gives as output a disposition to come through reliably with resilience in the face of challenges. In slogan form, faithfulness is resilient reliability.

We can now articulate the relationship between faith and faithfulness, on our view. As we've already indicated, they complement each other in relationships of mutual faith and faithfulness. Our theory explains why. When you put your faith in another, you are in a positive stance towards them coming through which, when all goes well, the other's faithfulness answers with a positive stance towards the same. And, conversely, when they are faithful, they are in a positive stance towards their coming through which, when all goes well, your faith in them answers with a positive stance towards the same. Similarly, when you put your faith in another, you are disposed to rely on them, even when it involves overcoming challenges which, when all goes well, their faithfulness answers by them being disposed to come through reliably, even when it involves overcoming challenges. And, conversely, when they are faithful, they are disposed to come through reliably, even when it involves overcoming challenges, which, when all goes well, your faith in them answers by being disposed to rely on them.

of course, faithfulness need not be a response to prior faith. You can be faithful, for example, as a parent, to your newborn daughter, even though she has yet to put faith in you. And faith need not be a response to prior faithfulness. You can put your faith in someone, for example, as a student of yours, even though they are not (yet) faithful to you in that capacity. Nevertheless, the reciprocity to which we call attention obtains frequently enough to be recognizably valuable in many of our most cherished relationships, such as friendship, marriage, and family relations.

Let's return to the Restricted Entailment Thesis. Recall that, according to that thesis, faithfulness entails affective faith. Clearly, on Resilient Reliance, this thesis is false. For, on that theory, relational faith is affective faith and yet faithfulness does not entail it. This a plus for the theory since we have three independent reasons to think that the Restricted Entailment Thesis is false. First, Eve is faithful to Adam as a spouse, but she 
lacks affective faith in him as a spouse. Second, just as when you attribute trustworthiness to someone you do not attribute to them something that entails affective trust, so when you attribute faithfulness to someone you do not attribute to them something that entails affective faith. ${ }^{12}$ Third, if we say faithfulness entails affective faith, we'll misrepresent the reciprocity involved in relationships of mutual affective faith and faithfulness. Our theory sheds light on why each of these three things is true.

Even though the Restricted Entailment Thesis is false, an even more restricted thesis might be true. We will now consider such a candidate suggested by remarks of Kvanvig's, and we will engage with his own theory of affective faith.

\section{Faith in, and faithfulness to, an ideal, cause, or long-term goal}

Kvanvig's theory of affective faith is similar to ours in some respects, but importantly different in others. After we present his theory, we will consider whether it justifies a more restricted thesis about the relationship between faith and faithfulness.

According to Kvanvig, affective faith

is an orientation of a person toward a longer-term goal, an orientation or disposition toward the holding of the goal or plan or project in the face of difficulties in its realization, one prompted by affections of various sorts and involving complex mental states that are fundamentally affective even if they involve cognitive dimensions as well. Such faith is a disposition to act in service of an ideal, whether that ideal is a political one such as equality and liberty for all people, or a sacred one, such as being part of the Kingdom of God. A plan, purpose, or goal is developed, and the culmination of this process involves a commitment by the individual to such a plan, and in following through on such a commitment the person displays the kind of faith that I am describing. People can be faithful to their commitments, or not, and when faithful, their actions express the disposition to act in service of an ideal ... [C]entral to the notion of an ideal for a person is, not a certain cognitive stance toward it, but rather a felt attraction regarding it. ${ }^{13}$

Here we see two things. First, Kvanvig identifies someone's affective faith with a disposition - for example, a commitment or an orientation - to act in service of an ideal, in the face of difficulties, motivated by a felt attraction to it or affections of various sorts. Second, according to Kvanvig, when their actions 'express' that disposition, they are 'faithful' to the ideal. So it is, we surmise, their faithfulness to the ideal that justifies a monotonic inference to affective faith. Note well: it's not faithfulness simpliciter of which Kvanvig speaks, but rather faithfulness to an ideal. This suggests that he has in mind a more restricted entailment thesis:

More Restricted Entailment Thesis. Faithfulness to an ideal entails affective faith.

What should we make of this more restricted thesis? Three points come to mind.

First, faithfulness to an ideal does not entail (affective) faith. For we can easily imagine that, in being faithful to Adam as a spouse, Eve expresses her faithfulness to the ideal of monogamous marriage, but it does not follow that she has faith in him as a spouse.

Second, faithfulness to an ideal does not entail faith in that ideal. After all, the owner of a company might be somewhat faithful to the ideal of equal pay for equal work, as evidenced by their supporting, advocating, and defending it in the public square, and yet, due to self-interest in a competitive environment, not be at all disposed to rely on it in 
deciding whether to equalize wages, in which case they qualify as not having faith in equal pay for equal work. Faithfulness to an ideal can come apart from faith in that ideal.

Third, we should not identify (affective) faith with a disposition to act in service of an ideal in the face of difficulties. That's because we can easily imagine that Adam has faith in Eve as a spouse, as expressed by his relying on her in that capacity in a variety of ways, but it does not follow that he is faithful to her as a spouse or to the ideal of monogamous marriage.

Even so, Kvanvig is onto something important here, namely that faithfulness to an ideal or a cause or a long-term goal, as he sometimes puts it - is a disposition to act in its service in the face of difficulty. In this connection, recall what we said at the outset of this article, namely that Abrahamic religions commend faithfulness to the ideals expressed by those religions. Any theory of faith and faithfulness should account for this phenomenon.

Our theory of faithfulness, Resilient Reliability, can do as much. For although it addresses faithfulness to people, we can plausibly extend it to faithfulness to an ideal or cause. For example, for you to be faithful to democracy or Black Lives Matter is for you to be disposed to come through reliably for them - for example, advocating and championing them, and defending them against assault and aggression - and to be resilient in the face of challenges to doing so in these and other ways, because of your positive stance towards their being realized or succeeding in the real world. In fact, we can also extend our theory of faith, Resilient Reliance, which addresses faith in people, to faith in an ideal or cause. For example, for you to have faith in democracy or Black Lives Matter, as an ideal or cause, is for you to be disposed to rely on them to guide your behaviour - for example, relying on the ideal being realized or the cause succeeding, or relying on it to guide you in the way you treat others, each of which can be done in any number of ways - with resilience in the face of challenges to doing so, because of your positive stance towards their being realized or succeeding in the real world.

Notice also that, on our theory, we can distinguish two ways in which we might act in service of an ideal or cause. One way involves actions characteristic of coming through for the ideal or cause, such as advocating and defending it. The other involves actions characteristic of relying on the ideal or cause, such as relying on it to be realized or successful, or allowing it to guide us in how we treat others.

Similarly, on our theory, we can distinguish two ways in which we might be committed to an ideal or cause. One way involves being committed to come through for it, that is, a disposition to do things on behalf of it, like advocating and defending it. When you follow through on that commitment, your following through expresses faithfulness to the ideal, coming through for it. A second way involves being committed to rely on it, that is, a disposition to allow it to do things on your behalf, such as guide you in how you treat others. When you follow through on that commitment, your following through expresses faith in the ideal, relying on it. Mutatis mutandis, this distinction applies to being committed to a person.

Upshot: even though the More Restricted Entailment Thesis is false, and even though affective faith is not a disposition to act in service of an ideal, Kvanvig draws our attention to phenomena any theory of faith and faithfulness should account for. Resilient Reliance and Resilient Reliability, which address faith in and faithfulness to people, can be extended to account for these phenomena: faithfulness to an ideal, acting in service of an ideal, and commitment to an ideal. Unlike Kvanvig's theory, our theory also explains the differences between faith in and faithfulness to an ideal, and different ways in which we might act in service of an ideal and be committed to it.

\section{People of faith}

While in some passages Kvanvig identifies affective faith with a disposition to act in service of an ideal, elsewhere something more takes the spotlight: 'a disposition to organize 
one's life around the pursuit of a course of behavior involving an ideal of some sort'. ${ }^{14}$ Kvanvig is absolutely right: in some of its manifestations, affective faith involves a disposition to organize, structure, and unify one's life around something that matters to one. In such cases, we find people of faith, people who live 'lives of faith', as he puts it. ${ }^{15}$ In this connection, Kvanvig observes that there are

unified approaches to life and approaches that involve disunity or disconnectedness. In the latter category are lives that instance the Humean view of causation: just one damn thing after another, with no attempt on the part of the individual in question to do anything beyond coping with whatever comes one's way ... In contrast to such patterns of behavior are approaches that pursue unity, that aim at connecting the multiplicities in experience into some sort of plan or purpose or understanding of things, and the boundary of such a search involves plans, purposes, and goals that are all-encompassing. ${ }^{16}$

We agree. People of faith often rely on a religious outlook to structure and unify their lives, and they devote themselves to a way of life associated with that outlook, as when Mother Teresa relies on Jesus and the Catholic religion, and serves Jesus among the poorest of the poor. We find this phenomenon in the irreligious as well. Madalyn Murray O'Hair and Richard Dawkins both display it when, having taken on board scientific naturalism early in their lives, they rely on that grand narrative to shape their plans and projects; and their work on behalf of its practical, social, and political implications bestows on their lives unity and purpose. They are people of secular faith.

Kvanvig allows that the extent to which faith unifies a life is a matter of degree. He denies that the "end or ideal must be all-encompassing, so inclusive that it unifies or harmonizes the self, and he affirms that "[m]ore restrictive types of faith are possible when the ideal is not quite so all-encompassing'. ${ }^{17}$ The extent to which faith provides 'structural unity or integrity to a personality over a wide variety of circumstances' admits of different depths and degrees, 'with the depth or degree of faith a measure of how wide the variety. ${ }^{18}$ We welcome these qualifications. To take them on board, we will replace talk of 'all-encompassing' ideals with 'life-organizing' ideals, and we will allow that multiple lifeorganizing ideals might unify different portions of a life, such as an ideal of marriage to structure one portion and an ideal of collegiality to structure another. Nonetheless, we will also allow that a life-organizing ideal might unify the whole of a life in an all-encompassing way.

Perhaps in life-organizing ideals we find another more restricted entailment thesis, a more plausible version of Kvanvig's monotonic inference from faithfulness to faith. Here it is:

Another More Restricted Entailment Thesis. Faithfulness to a life-organizing ideal entails affective faith.

By way of assessment, we make three points that parallel our points about the previous entailment thesis.

First, faithfulness to a life-organizing ideal does not entail affective faith. We all know of spouses whose faithfulness to their partner swamps other concerns so that their devotion to them consumes their lives. Suppose Eve is like that. Perhaps she thinks it's the divinely ordained role of a woman to live a life unified by faithfulness to Adam. His interests are her interests, and she recognizes no others that compare. Still, not even her faithfulness to the life-organizing 'ideal' of all-encompassing-husband-serving-monogamous-marriage entails (affective) faith. For despite her faithfulness to it she has no faith in Adam at all as a spouse. 
Second, faithfulness to a life-organizing ideal does not entail faith in that ideal. The owner of the company might organize the business portion of their lives around the ideal of equal pay for equal work, supporting, advocating, and defending it, and so qualify as being at least somewhat faithful to it, and yet whenever they attend to the bottom-line, they are not at all disposed to rely on that ideal in deciding whether to equalize wages, and so they qualify as not having faith in it. Of course, if a particular lifeorganizing ideal includes an imperative to put your faith in it, then faithfulness to it will entail faith in it. Suppose, for example, that 'put your faith in me' is one of God's commands, and also that this command, by God's lights, is so central to being faithful to those commands that, unless one obeys it, one does not count as being faithful to God's commands. It does then follow that you cannot be faithful to God's commands without faith in God. That's an important insight - one that is arguably particularly relevant to Abrahamic religions. But notice that the entailment doesn't follow from the nature of faithfulness itself. Rather, it follows from the nature of faithfulness plus the unless-clause. Notice also that it doesn't generalize because not every life-organizing ideal has that feature.

Third, we should not identify affective faith with a disposition to act in service of a lifeorganizing ideal in the face of difficulties. That's because we can have (affective) faith that does not imply faithfulness to a life-organizing ideal, as when we put our faith in Siri for directions to our son's wedding, or when we maintain faith in a promising student to be more studious, despite their current addiction to gaming. In short, we can have faith without being a person of faith.

Nevertheless, Kvanvig points to an important manifestation of faithfulness, one that any theory of faith and faithfulness should strive to accommodate. Our theory can do as much. That's because what distinctively characterizes a person of faith - the nature of their particularly impressive reliance on and devotion to the divine, as they understand it - can be usefully regarded as an admixture of faith and faithfulness. ${ }^{19}$ No religious person who failed completely to put and maintain their faith in the divine could be a person of faith; similarly, no religious person who utterly failed to be faithful to the divine could be a person of faith. And the same goes for a secular person of faith. Since we regard people of faith as possessing an admixture of affective faith and faithfulness, we prefer to describe them as people of faith/fulness to convey the admixture of affective faith and faithlessness that orients and unifies their lives. We can extend our theory to this manifestation of affective faith and faithfulness: for you to be a person of faith/fulness is for there to be something - for example, a worldview, grand narrative, ideal, or something else besides - such that you are disposed both to rely on it, to orient and unify your life, and to come through for it - for example, defending and championing it, or embodying it well - with resilience in the face of adversity, because of your positive stance towards its orienting and unifying your life. We might label the faith aspect of a person of faith/fulness orientational faith and the faithfulness aspect orientational faithfulness.

Upshot: Another More Restricted Entailment Thesis is false. While faith and faithfulness are often found together (e.g., in persons of faith) and while you can generate entailments from faithfulness to faith by building something functionally equivalent to the unless-clause into its content/object, affective faith is not to be identified with a disposition to act in service of a life-organizing ideal. Resilient Reliance and Resilient Reliability, however, plausibly extend to orientational faith and orientational faithfulness and account for them easily. We now take a brief detour from our search for a monotonic inference from faithfulness to faith in order to assess Kvanvig's take on another common manifestation of faith. 


\section{Propositional faith and propositional faithfulness}

Propositional faith is the faith one has when one has faith that $p$, for some proposition or state of affairs $p$, such as faith that the Party will win the election, even though the midnight count of the returns indicates otherwise, or faith that the basic Jewish, Christian, or Muslim story is true. Regarding this manifestation of faith, Kvanvig writes:

[P]ropositional faith can be understood in terms of faith itself, where the faith has a substrate involving mental states that have the proposition in question as their content, and where the crucial element in identifying a collection of mental states that are capable of constituting the requisite substrate for a given instance of propositional faith ... will be affective and conative rather than cognitive. ${ }^{20}$

By 'faith itself' Kvanvig means affective faith, that is, affectively grounded faith worth having, which, according to him, is the disposition to act in service of an ideal, perhaps even a life-organizing ideal, as we've seen. ${ }^{21}$

But propositional faith is not adequately understood 'in terms of faith itself' so understood, no matter where the state that takes a proposition as its object is located in one's mental architecture. To see why, suppose it's mid-Spring and you've got an itch to catch some trout. After a few minutes surfing the web, you decide that a weekend at Blue Lake, in the Sinlahekin Wildlife Area in Okanogan County, will scratch the itch. Your sons challenge your choice, and not without reason, but you declare your faith that the trout are biting at Blue. Suppose further that your faith is affectively grounded (say, because you have a 'felt attraction' towards trout biting at Blue), and suppose your faith is worth having (after all, if you get a fat holdover on your line, perhaps even a trophy trout, it will please you to no end, and you'll have bragging rights for the foreseeable future). Then your faith that trout are biting at Blue counts as affective faith. But it does not follow that trout are biting at Blue is a life-organizing 'ideal' or 'cause' or 'long-term goal' of yours. It only motivates you to go fishing for the weekend. Of course, your faith that trout are biting at Blue could involve a disposition to act in service of a life-organizing ideal or cause. To see what that might be like, browse Trout Unlimited, which is aptly named for 'people of trout faith'. But it need not. We can have all manner of propositional faith and yet lack these Kvanvigian dispositions.

Perhaps some kinds of propositional faith, for example faith that the basic Jewish, Christian, or Muslim story is true, should involve a disposition to act in service of a lifeorganizing ideal, or so those religions might say. But even so, it doesn't follow that anyone's faith actually involves that disposition. After all, our faith might fail to be as it should because, say, we compartmentalize it in such a way that we don't rely on it as an ideal to live by, much less a life-organizing one. Many theists, we wager, are familiar with this sort of phenomenon at some point in their journey.

Nevertheless, any theory of faith must accommodate this manifestation of faith, that is, propositional faith. Resilient Reliance can accommodate it. For we can easily extend the theory by saying that, for example, for you to have faith that your adolescent children will flourish as adults, or faith that the basic Jewish, Christian, or Muslim story is true, is for you to be disposed to rely on its being true, with resilience in the face of challenges to doing so, because of your positive stance towards its being true. As for propositional faithfulness - on which the literature is wholly silent - we can extend Resilient Reliability to it if we wish. For example, for you to be faithful to the proposition that all humans are created equal is for you to be disposed to come through reliably for its being true - for example, championing and defending it, or embodying it well - and to be resilient in doing so when challenges arise to acting in these and other ways in 
which you might come through on its behalf. We can easily generalize from these examples.

Upshot: Kvanvig's account of propositional faith is dubious at best, but Resilient Reliance and Resilient Reliability can be extended to that manifestation of faith, in addition to propositional faithfulness.

\section{The unity of faith and faithfulness}

We have treated relational, orientational, and propositional faith. We might wonder whether they share something important in common; something that is, rightly and strictly speaking, faith simpliciter, something of which they are its manifestations.

It is difficult to see how Kvanvig's theory can do so since, as we've seen, on his theory, faith is too narrowly circumscribed, and so it cannot accommodate the lion's share of relational and propositional faith, that is, instances of relational and propositional faith that do not involve a disposition to act in service of an ideal, whether life-organizing or not. However, our theory of faith provides the resources to unify relational, orientational, and propositional faith, as follows:

Faith simpliciter. For you to have faith (on some occasion) is for you to be disposed to rely on something in some way, with resilience in the face of challenges to doing so, because of your positive stance towards it coming through in that way,

where, depending on the particularities of the object and/or way, you manifest relational, orientational, or propositional faith. Notice that this way of understanding faith possesses a pleasing unity. Instead of three unrelated forms of faith - relational, orientational, and propositional faith - there is just faith simpliciter, manifested differently, depending on the particularities of the object and/or the way.

And something similar goes for relational, orientational, and propositional faithfulness. They too can be understood as manifestations of something important that is, rightly and strictly speaking, faithfulness simpliciter, which we can put in the abstract like this:

Faithfulness simpliciter. For you to be faithful (on some occasion) is for you to be disposed to come through reliably for something in some way, with resilience in the face of challenges to doing so, because of your positive stance towards coming through for it in that way,

where, depending on the particularities of the object and/or the way, you manifest relational, propositional, or orientational faithfulness. Like our understanding of faith simpliciter, this way of understanding faithfulness possesses an attractive unity. Instead of three unrelated forms of faithfulness - relational, propositional, and orientational faithfulness there is just faithfulness simpliciter, manifested differently, depending on the particularities of the object and/or the way.

We now turn to our final attempt to find a monotonic inference of the sort Kvanvig endorses.

\section{The virtues of faith and faithfulness}

According to Kvanvig, there are many things we mean to point to with our 'language of faith'; indeed, there are many 'kinds of faith'. ${ }^{22}$ We might wonder: what are the many kinds, and, what is it about each of them that makes them a kind of faith rather than a kind of something else? Rather than answering these questions, Kvanvig redirects 
them: 'what, in the neighborhood of things pointed to by the language in question, is worth having and thinking about? ${ }^{23}$ In answer, he writes: 'we should notice, first, that if faith is to be a virtue, it should be the stuff of which virtue is made - namely, a disposition of a certain sort'; indeed, 'it will have to be a trait of character'. ${ }^{24}$ Let's ignore the chasm between faith worth having and faith as a virtue and/or trait of character, and focus instead on the implied theory of faith and our search for a plausible monotonic inference from faithfulness to faith. With that aim in view, and building on our earlier findings, we have the following suggestion:

Yet Another More Restricted Entailment Thesis. Faithfulness to a life-organizing ideal entails the virtue of affective faith.

This can't be right, however. For, as we've seen, faithfulness to a life-organizing ideal does not entail faith in that ideal. They can come apart. Consequently, even if the ideal is good, and even if one is disposed to act faithfully with good judgement, and even if one's faithfulness is grounded in stable good motivations and values, one can be faithful to a life-organizing ideal while lacking the virtue of faith in that ideal.

Be that as it may, any theory of faith and faithfulness should explain how they might be virtues. Our theory can do as much. To see how, let's work our way up to it from an instance of relational faith, and let's suppose with Kvanvig and other neo-Aristotelians that every virtue is a character trait. Suppose you have faith in David as a friend. On our theory, that is, most fundamentally, for you to be disposed to overcome challenges to relying on David as a friend. Problem: your faith in David as a friend isn't a character trait and so it isn't a virtue.

Even so, Resilient Reliance can accommodate the neo-Aristotelian. First, we abstract away from particular objects of faith, like David, and particular capacities, like friendship. When we do that, we can say that for you to have faith as a virtue is for you to be disposed to overcome challenges to relying on those in whom you repose faith. And we can allow that the degree to which you possess the virtue depends on, inter alia, the variety of circumstances in which you would be disposed to overcome challenges to relying on them. However, virtues are grounded in one's stable motivations and values, and so we can add that for you to have faith as a virtue is for you to be disposed to overcome challenges to relying on those in whom you repose faith because of your stable motivations and values. ${ }^{25}$ This is not enough, though. After all, as indicated above, someone might be stably disposed to overcome challenges to relying on those in whom they repose faith but lack the virtue of faith, either because they lack good judgement about who, when, or what to put faith in or because their disposition is grounded in bad motivations and values. We can handle this point by saying that for you to have faith as a virtue is for you to be disposed to appropriately overcome challenges to relying on those in whom you repose faith, and to do so because of your stable good motivations and values, where 'appropriately' signals good judgement and grounding in good motivations and values. For similar reasons, we can say that the virtue of faithfulness, on an extension of Resilient Reliability, is a disposition to appropriately overcome challenges to coming through reliably for someone because of your stable good motivations and values.

Upshot: Yet Another More Restricted Entailment Thesis seems questionable at best; moreover, by way of plausible extensions, Resilient Reliance and Resilient Reliability can account for the virtues of faith and faithfulness.

A brief summary is in order. Kvanvig (2016) endorsed 'an identification of affective faith with faithfulness'. In reply to Howard-Snyder's Adam and Eve case, he denied that he endorsed 'an identification of affective faith with faithfulness'. Instead, he endorsed 'a kind of inference from faithfulness to faith', specifically a 'monotonic inference'. 
Despite our best efforts, we've been unable to find in Kvanvig's writings any monotonic inference worth drawing. Further, we found the variety of ways in which he characterizes affective faith implausible. We proposed an alternative theory of affective faith and faithfulness, Resilient Reliance and Resilient Reliability. We explained how faith is related to faithfulness on that theory, how it could be extended to a variety of manifestations of faith and faithfulness, including faith in and faithfulness to an ideal, how it could unify all those manifestations under a single, comprehensive theory of faith, and how it could account for the virtues of faith and faithfulness.

We now turn to the biblical material Kvanvig puts forward to support his view. We will argue that (i) our theory handles it at least as well as his theory and (ii) none of that material justifies a nonmonotonic inference from faithfulness or faithful behaviour to affective faith.

\section{'The Hebrews inference' and other biblical material}

Kvanvig claims his theory of faith is "well suited to explaining important and central examples of religious faith, such as the faith displayed by Abraham in leaving Mesopotamia for Canaan'. ${ }^{26}$ Notably, he relies on the author of The Letter to the Hebrews - according to whom Abraham obeyed God's commandment to leave Mesopotamia 'by faith' - to draw 'the Hebrews inference', that is 'the inference from faithful behavior to underlying faith'. ${ }^{27}$ What should we make of 'the Hebrews inference'?

Here's what Kvanvig writes:

The narrative in Genesis 12 is sparse - we are told only that the Lord said, 'Go,' and, 'So Abraham went'. Later accounts of the matter attribute his behavior to faith: 'By faith Abraham, when he was called to go out into a place which he should after receive for an inheritance, obeyed; and he went out, not knowing whither he went' (Heb 11.8). The explanation here is quite natural: Abraham is faithful to the divine command to leave for Canaan; his doing so is 'by faith'. It is also a fundamentally noncognitive feature of Abraham that undergirds his behavior. We do not know the details, but some possibilities come to mind easily: perhaps he experiences a felt obligation to a divine command, or perhaps a deep attraction to a life guided by a divine being and being the recipient of divine favor and blessings; perhaps these were mixed with fear of divine displeasure with disobedience. What we can be confident of, however, is that the source of his behavior and the attitude that underlies it are just as fundamentally affective as they are in the case of the Little League pitcher. In both cases, affective faith involves faithfulness to an ideal. ${ }^{28}$

And later: 'It is, in a word, a rendering of Abraham's faith in terms of his faithfulness that is crucial to the story, which is the fundamental point made about the affective faith characterized here. ${ }^{29}$

We doubt that any nonmonotonic inference from Abraham's faithful behaviour to underlying faith will be justified. There are different kinds of nonmonotonic inference, for example, enumerative induction, statistical induction, argument by analogy, and so on. Let's suppose that the most plausible nonmonotonic inference in Abraham's case is argument to the best explanation, as Kvanvig appears to suggest. In that case, if we can find readings of the Abraham story that are consistent with the account of it in Hebrews, and if each of them is at least as plausible as Kvanvig's reading, and if none them justifies an inference from faithful behaviour to faith as the best explanation of that behaviour, then Kvanvig's inference from faithful behaviour to faith will not be justified. Here are three readings that fit the bill. 
First reading: inferring faithfulness from faithful behaviour. The word 'faith' in 'By faith, Abraham obeyed...' is a translation of the noun form of a class of Greek words with the pist- stem: pístis (noun), pisteúo (verb), and pístos (adjective). The semantic domain of the pistis lexicon ranges widely, leaving translators to choose between faith, trust, reliance, faithfulness, trustworthiness, reliability, steadfastness, allegiance, loyalty, belief, and confidence. Suppose we take as non-negotiable Kvanvig's premise that Abraham's obedience is 'faithful behaviour'. In that case, since faithful behaviour is behaviour done by faithfulness, we would translate 11.8 as 'By faithfulness, Abraham obeyed...' But then we would exchange Kvanvig's premise that the author of Hebrews (correctly) explains Abraham's obedience as done 'by faith' for the premise that the author (correctly) explains Abraham's obedience as done 'by faithfulness', in which case the best explanation of Abraham's obedience, his faithful behaviour, is not faith but faithfulness.

Second reading: inferring faith from faithish behaviour. According to Kvanvig, when we look at the narrative of Abraham leaving Mesopotamia, 'we are told only that the Lord said, "Go," and, "So Abraham went". ${ }^{30}$ But this characterization omits important details. Here's the passage, in full:

Now the LORD said to Abram, "Go from your country and your kindred and your father's house to the land that I will show you. I will make of you a great nation, and I will bless you, and make your name great, so that you will be a blessing. I will bless those who bless you, and the one who curses you I will curse; and in you all the families of the earth shall be blessed.' So, Abram went, as the LoRD had told him ... ${ }^{31}$

With the actual narrative in view, we see not only "the LoRD said, "Go," and, "So, Abraham went", we see in between God's multifaceted and extensive covenant with Abraham.

This reading foregrounds Abraham's exemplary reliance on God, which perseveres through various obstacles despite uncertainties about whether God will be faithful to the covenant. In this connection, Raymond Brown takes it that 'Abraham recognized that in responding to God's demands he must place his entire reliance on the God who not only called him, but would guide his steps, meet his needs and prepare his future'. ${ }^{32}$ Likewise, Abraham relies on God to make a great nation of him, to bless all the families of the earth through him, etc. Further, Abraham's reliance on God explains why the author of Hebrews describes Abraham's leaving as an act of obedience done 'by faith'. By relying on God as one with the standing to issue the command in the first place, by relying on God as one who has in view his own good and the good of his immediate family, and by relying on God as one who will be faithful as they travel through hostile territory - Abraham obeyed. $^{33}$ In addition, the author of Hebrews tell us that it was because Abraham considered God to be faithful to the promise of an heir, even though Abraham and Sarah were too old to have children, that Abraham relied on God to receive 'power of procreation'. ${ }^{44}$ Moreover, the author indicates that by relying on God's ability 'even to raise someone from the dead', Abraham 'offered up Isaac'. ${ }^{35}$ As narrated in both Genesis and Hebrews, Abraham's story displays a disposition to rely on God, with resilience in the face of challenges, for something that mattered to him, the fulfilment of God's promise.

To be sure, Abraham's reliance on God had its ups and downs, as Eleonore Stump documents. ${ }^{36}$ But the overall narrative arc of Abraham's story has him maintaining faith in God, from beginning to end, despite his ups and downs, culminating in his astonishing reliance on God's power and goodness when he raises his arm to obey the command to offer Isaac. $^{37}$ 
In short, on the second reading, the so-called 'Hebrews Inference' is not an inference from faithful behaviour to underlying faith. Rather, it is an inference from faithish behaviour to underlying faith. The explanation is quite natural: Abraham puts his faith in God when he leaves Mesopotamia; his leaving is 'by faith'. On this reading, the exemplary behaviour of Abraham picked out by the author of Hebrews - for instance, his waiting on God, his obeying God, and his sacrificing to God - is better characterized as 'faithish' rather than 'faithful' behaviour, in which case the premise of Kvanvig's inference is false.

Third reading: inferring both faith and faithfulness from both faithish and faithful behaviour. Interestingly, faithfulness and faith can issue in the same behaviour. Granted: in obeying God, Abraham exhibited faithfulness to God's command. And, granted: throughout the story, when Abraham's reliance on God was at low ebb, he excelled in faithfulness to God. Nevertheless, in obeying God's command, and elsewhere in the story, Abraham not only exhibited faithfulness to God but also faith in God, relying on God in the ways the second reading exhibits. In that case, when Hebrews says that 'By pistis, Abraham obeyed', faith and faithfulness are both in view. Both motivated Abraham to leave when God said go, as they might have jointly motivated behaviour elsewhere in the story.

That pistis can point at once to both faith and faithfulness has considerable currency. ${ }^{38}$ James Dunn observes that 'Abraham's trust in God was embodied in and expressed by his obedience. His faith and faithfulness were two sides of the same coin; it was the same word, and the same attitude and action expressed by that word'. ${ }^{39}$ Harold Attridge says the pistis by which Abraham obeyed 'is obedient fidelity and trusting belief at the same time and both components are essential. ${ }^{40} \mathrm{~N}$. T. Wright avers that, for Paul, 'this pistis, this heartfelt trust in and allegiance to the God revealed in Jesus, was the vital marker, the thing that showed whether someone was really part of this new community or not'. ${ }^{41}$ Teresa Morgan intimates that in the Graeco-Roman world, pistis and fides were often used to express, at once, both the faith and the faithfulness sides of the pistis/ fides lexica, as when people praised the pistis/fides of a magistrate and, in one fell swoop, highlighted his reliance on the people, the laws, and the gods, as well as his faithfulness to them. ${ }^{42}$

Each of these three readings is consistent with the account of Abraham's story in Hebrews, each is at least as plausible as Kvanvig's reading, and none justifies an inference from faithful behaviour to faith as the best explanation of that behaviour. Therefore, no inference from faithful behaviour to faith as the best explanation of that behaviour is justified.

Kvanvig also appeals to an inference from faithfulness or faithful behaviour to underlying faith when he explains the behaviour of those who were attracted to Jesus, as expressed by the author of The Gospel According to John: 'we beheld his glory, the glory as of the only begotten of the Father, full of grace and truth'. ${ }^{43}$ The experience of beheld glory, Kvanvig says, is not fundamentally cognitive; rather, 'the experience and the attachment to an ideal which results, are fundamentally affective'. He continues:

So the source of Johannine faith is clearly affective. But the source is not the faith, for if John had beheld the glory in question, and then decided to return to his ordinary life, he would have been in the same faithless category as the rich young ruler, who with sadness went back to his wealth when hearing the call to a different life. For faith to be present is for something else to be found here. And notice, what more is needed is ... the orientation of a person in service of one ideal rather than some other. What is needed is a disposition to follow and for that disposition to be displayed in action ... But when we find faithfulness to an ideal, displaying behavior that is an expression of a disposition whose source and identity are found in the 
affective origins of the attraction of the ideal, we can not only infer the presence of faith, but have located its nature as well. ${ }^{44}$

Kvanvig suggests here that John's attraction to Jesus and the faithful behaviour that results from it, that is, his following Jesus, is best explained by John's faith, which Kvanvig identifies as an orientation (disposition) to act in service of an ideal. Indeed, Kvanvig even goes so far as to assert that John's following Jesus upon beholding his glory requires such a disposition: 'what more is needed is ... the orientation of a person in service of one ideal rather than some other'. So it is, Kvanvig suggests, faithfulness or faithful behaviour justifies an inference to underlying faith.

We object. First, for reasons we have already mentioned, we should not identify faith with 'the orientation of a person in service of one ideal rather than some other'. Second, a disposition to act in service of an ideal is not 'needed' to explain John's following Jesus upon beholding his glory. Third, there are three other explanations of John's following Jesus upon beholding his glory, each of which is consistent with John's Gospel and each of which is at least as plausible as Kvanvig's reading; moreover, none of them justifies an inference from faithful behaviour to faith as the best explanation of that behaviour. (i) Hold fixed the claim that John's following Jesus is faithful behaviour. In that case, John's faithfulness to Jesus as Lord rather than his faith in Jesus as Lord better explains John's behaviour upon beholding Jesus's glory. (ii) John's following Jesus is faithish behaviour, in contrast with faithful behaviour. After all, we can easily imagine that John's following Jesus manifested a disposition to rely on Jesus as Lord, and so to follow his example and instruction - perhaps in the way an apprentice relies on a journeyman, or a servant relies on a master, or a student relies on a teacher or rabbi. In that case, John's faith in Jesus rather than his faithfulness to him better explains John's following Jesus upon beholding the glory of Jesus. (iii) John's following Jesus is both faithful and faithish behaviour. After all, there's ample evidence in the world of John's narrative that (a) Jesus relied on John and the rest of the disciples for a variety of things, for example, to follow his example and instruction, and that, to a modest degree, they came through for him on that score, and (b) they relied on Jesus as Lord, as highlighted by the second reading. In that case, John's faithfulness to and faith in Jesus as Lord together best explain John's following Jesus upon experiencing Jesus's glory. In light of (i)-(iii), the inference from faithfulness or faithful behaviour to underlying faith is unjustified.

A third bit of biblical material Kvanvig adduces in favour of his view is the Hebrew word 'ěmûnāh. In one passage, Kvanvig writes: 'a proper understanding of the development of Judaism places loyalty and commitment to Yahweh as the central feature to note concerning the use of the term 'émûnāh and its variants, translated as "faith" when in noun form'. ${ }^{45}$ The suggested inference is clear: 'ěmûnāh is used to point to faithfulness; 'ěmûnāh is translated as 'faith' in its noun form; so, the inference from faithfulness to faith is justified.

Kvanvig rightly emphasizes the centrality of loyalty and commitment to 'ěmûnāh, which can also point to firmness, steadfastness, trustworthiness, and faithfulness. ${ }^{46}$ But we object to the second premise. While 'ěmûnāh can be translated as 'faith', it is very rarely translated in that way. Of the forty-nine occurrences in the Hebrew Bible, perhaps only in Habakkuk 2.4 is it translated 'faith', 'the righteous live by their/his faith', and even here it is debatable, as Edmund Perry notes:

The Gordian knot of the statement ['the righteous live by their faith'] is the word 'emuna, translated "faith" here, but elsewhere and more often translated 
"faithfulness." Is it the reliance or the reliability of the righteous which is intended in this passage ? $^{47}$

Or both? Our point, though, is that Kvanvig's claim that 'ĕmûnāh is 'translated as "faith" when in noun form' is simply false. Moreover, it does not follow from the fact that 'ěmûnäh can be translated as 'faith' that an inference from faithfulness to faith is justified, just as it does not follow from the fact that 'ěmûnāh can be translated as 'reliance' that an inference from reliability to reliance is justified.

Our theory of faith and faithfulness - according to which faith is resilient reliance and faithfulness is resilient reliability - fits better with the following kinds of observations by scholars of the Hebrew scriptures:

In English, the word 'faith' refers to an attitude of belief, trust or reliance in the word or character of another, whereas the word 'faithfulness' refers to a virtue or quality of character seen in ongoing dependable action. Both meanings are found in the Hebrew caman word group and in the biblical story. Abraham had faith in God (Gen. 15:6), but is more commonly said to be faithful to God. Later Jewish writings emphasize the latter (e.g. 1 Macc. 2:52). Both meanings, trust in another and faithfulness to the other, make sense within the context of personal relationships. ${ }^{48}$

While we deny that the word 'faithfulness' must refer to a virtue or quality of character - after all, you can be faithful to a particular individual for a particular thing without having the character trait or the virtue of faithfulness - no one who endorsed the spirit of these observations would be the least bit tempted to draw an inference from faithful behaviour to underlying faith motivating that behaviour. There are more plausible options, notably an inference from faithful behaviour to underlying faithfulness motivating it.

What we've said here about Kvanvig's treatment of Hebrews 11 and Genesis 12, the Johannine attraction to Jesus, and 'ěmûnāh contains the resources to undermine Kvanvig's appeal to other biblical material in defence of his theory of affective faith and his inferences from faithfulness and faithful behaviour to underlying faith. Moreover, as displayed, we can draw on Resilient Reliance and Resilient Reliability to explain at least as plausibly the biblical material to which Kvanvig appeals.

\section{Concluding remarks}

In closing, we turn to Low Dog, the Lakota war chief whom Kvanvig regards as an exemplar of faithfulness. ${ }^{49}$ As the Battle of Little Big Horn gets underway on 25 June 1876, Low Dog stirs his warriors to fight with the proclamation, 'Today is a good day to die! Follow me!' Low Dog refuses the subservient way of life that the United States government demanded of him and his people, and he regards his commitment to this cause as important enough to die for if necessary. Clearly the cause and its implicit ideals matter deeply to him, as they did to the Lakota more generally. The historical record is silent about his cognitive attitudes - about whether he thought there was a very good chance that his cause might prevail on this day, for himself and his people or, in the long run, for their descendants. But he did have views about what pursuing and honouring the ideals in this situation called for, and views about the sorts of actions that might make a difference to those ideals being realized.

Plausibly enough, Low Dog recognized the chance of success was not high, as Kvanvig suggests, but he still took the cause to be worth fighting for. Seen in this light, some of Low Dog's actions are naturally viewed as expressions of faithfulness to a cause. For 
example, he bravely goes to war with his fellows, defending the cause in the face of cannon, sabre, and shot, willingly giving his life if need be to come through for the realization of the ideals shared by his people. Perhaps other actions of Low Dog are expressive of faith in a cause. Perhaps the cause involves ideals expressible in principles the truth of which he relies on to guide his decisions and how he treats others. Plausibly enough, he also relies on those who follow him into battle to fight bravely. Notice that Low Dog displays resilience in the face of difficulty, both with respect to relying on, and coming through for, the Lakota people, ideals, and cause for which he was willing to die.

Notably, in none of this is there any need to 'identify' faithfulness with faith. Nor are there any grounds to draw a monotonic or nonmonotonic inference from faithfulness or faithful behaviour to underlying faith. Perhaps Low Dog possessed both the virtue of faith and the virtue of faithfulness. If so, there's nothing in this embellishment of his story that justifies an explanation of his faithful behaviour at Little Big Horn in terms of the virtue of faith. That's because there's a better explanation at hand: his faithful behaviour at Little Big Horn was expressive of his faithfulness to the Lakota people, cause, and ideals, which was a natural consequence of the virtue of faithfulness that he possessed.

We have considered two views that make very different claims about what faith and faithfulness are and how they are related. According to Resilient Reliance, for you to have (affective) faith in someone for something is, most fundamentally, for you to be disposed to rely on them to come through with respect to it, with resilience in the face of challenges to doing so. On Resilient Reliability, for you to be faithful to someone for something is, most fundamentally, for you to be disposed to come through reliably with respect to it, with resilience in the face of challenges to doing so. We explored multiple characterizations of Kvanvig's theory of affective faith, and we specified several theses about the relation between faith and faithfulness suggested by what he wrote and said. In each case, we gave reasons to think the theory is implausible and that the alleged relationship does not hold, and we displayed how our theory explained the data to which he appealed at least as well as his theory - but without the independently implausible identification of faith with faithfulness, or any implausible inference from faithfulness or faithful behaviour to underlying faith. Commitments to ideals and dispositions to act in service of them are importantly related to faith and faithfulness. As we indicated at the outset, such commitments and dispositions are central to the practice of Abrahamic religion. We have offered a way of thinking about how they can be accounted for in terms of Resilient Reliance and Resilient Reliability. We hope, therefore, to have not only shed light on what faith and faithfulness are and how they related to each other, especially in relationships of mutual faith and faithfulness, such as the covenantal relationships that stand at the heart of Abrahamic religions, we also hope to have shed some light on what it is to be faithful to and to maintain faith in the ideals to which Abrahamic religion calls its adherents. $^{50}$

\section{Notes}

1. Morgan (2015).

2. A more comprehensive articulation and defence of our theory awaits another occasion. We focus only on engaging Kvanvig's theory in the indicated way.

3. Kvanvig (2016), 14; cf. Idem (2018), 19, 27. See also Idem (2018), 17, 19, 21, 32, 36, 51, 54, 69, 83, 104, 146, 200, and Idem (2016), 11, 12, 13, 18, 23, where affective faith is described as 'prompted by affections', 'rooted in the affections' or a 'felt attraction' to its object, possessed of an 'affective source and sustenance', 'motivated by affective states', and 'the kind of faith worth having'.

4. Kvanvig (2016), 14; emphasis added; cf. Idem (2018), 19, 27. Here we register a disagreement with Kvanvig. While, strictly speaking, 'faithful' is the adjectival form of 'faith', if you were to use 'faithful' to point to someone who was full of faith or especially characterized by faith, your audience would probably think you were confused, 
fail to understand you, or perhaps take you to be drawing on a rare, archaic, or obsolete meaning. That is because, as Alston and others have pointed out, in the way that 'faithful' is used in modern English, it is like 'pitiful' or 'shameful', not 'hopeful' or 'merciful'. To be pitiful is to be an appropriate object of pity; it is not to be full of pity or especially characterized by pity. To be shameful is to be an appropriate object of shame; it is not to be full of shame or to be especially given to shame. Likewise, to be faithful is to be an appropriate object of faith; it is not to be full of faith or especially characterized by faith. For this reason, if modern English users were to adopt for common use an adjectival form of 'faith' that pointed to being full of faith or being especially characterized by faith, 'faithish' would be preferable to 'faithful', to avoid confusion. Something similar can be said for 'faithfully'.

At any rate, we are theorizing about faith and faithfulness as psychological phenomena, not about how words that refer to them are used. One upshot of our theorizing is that, even if the adjective 'faithful' were to be used in modern English to point either to being especially characterized by faithfulness or to being especially characterized by faith, so as to avoid confusion we would recommend restricting its use to point consistently to the property of people, acts, or things especially characterized by faithfulness and suggest 'faithish' as the missing adjective to point consistently to the property of being especially characterized by faith. Similarly, we would recommend that the noun 'faith' be used consistently to point to faith, 'faithfulness' to faithfulness, and 'faith and faithfulness' or 'faith(fulness)' to point to both at once. Moreover, unlike some other natural languages such as Greek and Latin, which provide verb forms for the nouns pistis and fides, modern English lacks or rarely avails itself of a verb form for 'faith'. We would be happy to see 'faithe', with a distinguishing 'e', tasked for this role. 5. Kvanvig can be interpreted elsewhere as affirming the Identity Thesis. See Kvanvig (2016), 12-13, 'Faith ... regarding it', cf. Idem (2018), 17-18; Idem (2016), 14, 'The narrative ... to an ideal', cf. Idem (2018), 27-28; Idem (2016), 17, 'In a word ... characterized here', cf. Idem (2018), 31.

6. Howard-Snyder (2014).

7. Kvanvig (2014); emphasis added. A monotonic inference is one which is such that, necessarily, if the premises are true, then the conclusion is true, and so adding more information to the premises cannot render the inference invalid. A nonmonotonic inference is one that is not monotonic.

8. See Alston (1996) (acceptance), Audi (2011) (trust), Pojman (1986) (hope), McKaughan (2013) and (2016) (trust, acceptance, hope, non-zero subjective probability), Schellenberg (2013) (imaginative assent), Jackson (2021) (credence), and Howard-Snyder (2019) (beliefless assuming). While positive cognitive states typically have propositional content, we will allow for imagistic cognitions such as cognitive maps as well as perceptual states. For a more thorough explanation of positive cognitive states, see Howard-Snyder (2019).

9. Cf. Alston (1996); Adams (1999); Audi (2011); Howard-Snyder (2013). Some pistologists include in the conative state a positive evaluation of the person coming through, regarding their coming through as a good or desirable thing.

10. Here we agree with Kvanvig who also treats faith functionally. See Kvanvig (2018), chs 2 and 5, and sect. 4.3.

11. Alston (1996), 13.

12. See, for example, Jones (1996) on affective trust.

13. Kvanvig (2016), 12-13; emphasis added; cf. Idem (2018), 17-18. See also Idem (2016), 14, and Idem (2018), 27-28, for emphasis on faithfulness to an ideal.

14. Kvanvig (2018), 146, emphasis added; cf. Dewey (1934).

15. Cf. Kvanvig (2018), 16.

16. Kvanvig (2016), 11; cf. Idem (2018), sect. 2.4, 16, 60-63.

17. Kvanvig (2018), 60.

18. Ibid., 16.

19. Cf. Pace and McKaughan (2020).

20. Kvanvig (2018), 54.

21. Ibid., 16 .

22. Ibid., 1, 9, 103.

23. Ibid., 7. Elsewhere, he expresses more optimism about a unified account; see ibid., 55.

24. Ibid., 7, 13. Cf. 'Our beginning assumption is that faith is a virtue' (ibid., 9), and 'a basic tenet regarding faith is that it is ... something which is supposed to be a virtue and somehow central to a well-lived life' (ibid., 2, 103). We make no such assumption. We allow that people can have faith even if they lack both the trait and the virtue.

25. On why virtues are grounded in stable motivations and values, see Baehr (2011) and Battaly (2015).

26. Kvanvig (2016), 14; Idem (2018), 27.

27. Kvanvig (2016), 18; cf. Idem (2018), 32. As we've seen, Kvanvig elsewhere speaks of an 'inference from faithfulness to faith' instead of an inference from faithful behaviour to faith (Kvanvig (2016), 22; Idem (2018), 36). Obviously, faithfulness is not to be identified with faithful behaviour.

28. Kvanvig (2016), 14, emphasis added; cf. Idem (2018), 27-28. 
29. Kvanvig (2016), 17; cf. Idem (2018), 31.

30. Kvanvig (2016), 14, emphasis added; cf. Idem (2018), 27.

31. Genesis 12.1-4a.

32. Brown (1988), 204.

33. Hebrews 11.9-10.

34. Hebrews 11.11-12; Genesis 15.

35. Hebrews 11.17-19; Genesis 22.

36. Stump (2010), ch. 11.

37. Genesis 22. Thiselton $(2003,1473-1474)$ has the author of Hebrews emphasizing Abraham's 'trust' and 'trustful faith' in God, which lies on the faith/trust/reliance side of the pistis lexicon, not the faithfulness/trustworthiness/reliability side.

38. Cf. McKaughan (2017); Pace and McKaughan (2020).

39. Dunn (2007), 409.

40. Attridge (1989), 308.

41. Wright (2018), 91.

42. Morgan (2015), 75; cf. 5, 30-31, 120.

43. John 1.14 .

44. Kvanvig (2016), 23, emphasis added; cf. Idem (2018), 36-37.

45. Kvanvig (2018), 14.

46. Brown et al. (1977), 53; Koehler et al. (2001), 62.

47. Perry (1953), 252.

48. Noble (2016), 322.

49. Kvanvig (2018), viii.

50. A grant from the John Templeton Foundation supported this publication. The opinions expressed in it are those of the author(s) and might not reflect the views of the John Templeton Foundation. We are grateful to Jon Kvanvig for insightful conversation about faith over the years. For comments on earlier drafts of the present article, we thank Matthew Bates, Frances Howard-Snyder, Hud Hudson, Christian Lee, Michael Pace, Gavin Partington, Neal Tognazzini, Ryan Wasserman, Dennis Whitcomb, Dean Zimmerman, and workshop audiences at the University of Manchester in May 2019 and at Chapman University in June 2019.

\section{References}

Adams RM (1999) Finite and Infinite Goods: A Framework for Ethics. New York: Oxford University Press.

Alston WP (1996) Belief, acceptance, and religious faith. In Jordan J and Howard-Snyder D (eds), Faith, Freedom, and Rationality. Lanham, MD: Rowman \& Littlefield, pp. 3-27, 241-244.

Attridge HW (1989) The Epistle to the Hebrews: A Commentary on the Epistle to the Hebrews. Philadelphia: Fortress Press.

Audi R (2011) Rationality and Religious Commitment. New York: Oxford University Press.

Baehr J (2011) The Inquiring Mind. New York: Oxford.

Battaly H (2015) Virtue. Malden, MA: Polity Books.

Brown R (1988) The Message of Hebrews: Christ Above All. Downers Grove, IL: InterVarsity Press.

Brown F, Driver SR and Briggs CA (1977) Enhanced Brown-Driver-Briggs Hebrew and English Lexicon. Oxford: Clarendon Press.

Dunn JDG (2007) Faith, faithfulness. In Sakenfeld KD (ed.), The New Interpreter's Dictionary of the Bible, vol. 2. Nashville, TN: Abingdon Press, pp. 407-423.

Howard-Snyder D (2013) Propositional faith: what it is and what it is not. American Philosophical Quarterly 50, 357372.

Howard-Snyder F (2014) Comments on Kvanvig's 'The Idea of Faith as Trust: Lessons in NonCognitivist Approaches to Faith'. Faith and Reason: Themes from Swinburne, Purdue University. Available at https://swinburneconference.wordpress.com/session-1/. Accessed 10 June 2021.

Howard-Snyder D (2019) Can fictionalists have faith? It all depends. Religious Studies 55, 447-468.

Jackson E (2021) Belief, faith, and hope: on the rationality of long-term commitment. Mind 130, 35-57.

Jones K (1996) Trust as an affective attitude. Ethics 107, 4-25.

Koehler L and Baumgartner W and Stamm J (2001) The Hebrew and Aramaic Lexicon of the Old Testament, vol. 1, trans. M. E. J. Richardson. Leiden: Brill.

Kvanvig JL (2014) The Idea of Faith as Trust: Lessons in NonCognitivist Approaches to Faith. Faith and Reason: Themes from Swinburne, Purdue University. Available at https://swinburneconference.wordpress.com/session-1/. Accessed 10 June 2021. 
Kvanvig J (2016) The idea of faith as trust: lessons in noncognitivist approaches to faith. In Bergmann M and Brower JE (eds), Reason and Faith: Themes from Richard Swinburne. New York: Oxford University Press, pp. 4-25. Kvanvig J (2018) Faith and Humility. New York: Oxford University Press.

McKaughan DJ (2013) Authentic faith and acknowledged risk: dissolving the problem of faith and reason. Religious Studies 49, 101-124.

McKaughan DJ (2016) Action-centered faith, doubt, and rationality. Journal of Philosophical Research 41, 71-90.

McKaughan DJ (2017) On the value of faith and faithfulness. International Journal for Philosophy of Religion 81, 7-29.

Morgan T (2015) Roman Faith and Christian Faith: Pístis and Fides in the Early Roman Empire. New York: Oxford University Press.

Noble TA (2016) Faith. In Davie M, Grass T, Holmes SR, McDowell J and Noble TA (eds), New Dictionary of Theology: Historical and Systematic, 2nd edn. London; Downers Grove, IL: InterVarsity Press, pp. 322-323.

Pace M and McKaughan DJ (2020) Judaeo-Christian faith as trust and loyalty. Religious Studies, 1-31. doi:10.1017/ S0034412520000153.

Perry E (1953) The meaning of 'emuna in the Old Testament. Journal of Bible and Religion 21, 252-256.

Pojman L (1986) Faith without belief. Faith and Philosophy 3, 157-176.

Schellenberg JL (2013) Evolutionary Religion. New York: Oxford University Press.

Stump E (2010) Wandering in Darkness: Narrative and the Problem of Suffering. Oxford: Oxford University Press.

Thiselton AC (2003) 'Hebrews'. In Dunn JDG and Rogerson JW (eds), Eerdmans Commentary on the Bible. Grand Rapids, MI: Eerdmans, pp. 1451-1482.

Wright NT (2018) Paul: A Biography. San Francisco: HarperOne.

Cite this article: McKaughan DJ, Howard-Snyder D (2022). Theorizing about faith and faithfulness with Jonathan Kvanvig. Religious Studies 58, 628-648. https://doi.org/10.1017/S0034412521000202 